\title{
A case of right heart failure in a 48-year-old patient with constrictive pericarditis treated by pericardiectomy
}

\author{
DOgnjen Čančarević*, \\ Sandra Jakšić \\ Jurinjak', \\ DBoris Starčević1, \\ DMartina Menegoni², \\ DDaniel Unić ${ }^{1}$
}

'University Hospital Dubrava, Zagreb, Croatia

${ }^{2}$ General Hospital "Dr. Josip Benčević", Slavonski Brod, Croatia

RECEIVED:

February 28, 2019

ACCEPTED:

March 24, 2019

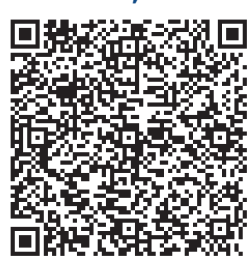

KEYWORDS: pericardium, constriction, right heart failure.

CITATION: Cardiol Croat. 2019;14(3-4):45. | https://doi.org/10.15836/ccar2019.45

*ADDRESS FOR CORRESPONDENCE: Ognjen Čančarević, Klinička bolnica Dubrava, Avenija Gojka Šuška 6, HR-10000 Zagreb, Croatia. / Phone: +385989811565 / E-mail: ognjen200468@gmail.com

ORCID: Ognjen Čančerević, https://orcid.org/0000-0002-1285-8042 • Sandra Jakšić Jurinjak, https://orcid.org/0000-0002-7349-6137 Boris Starčević, https://orcid.org/0000-0002-3090-2772 • Martina Menegoni, https://orcid.org/0000-0002-4295-9039 Daniel Unić, https://orcid.org/0000-0003-2740-4067

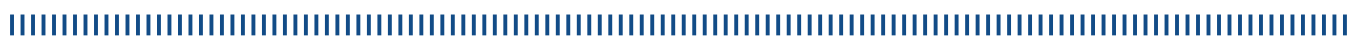

Background: Constrictive pericarditis (CP) is uncommon cause of predominantly right heart failure ${ }^{1}$. In CP pericardium creates a stiff ventricular-pericardial unit which leads to increased diastolic pressures, limitation of ventricular relaxation and equalization of intracardiac diastolic pressures producing „single diastolic chamber"2.

Case report: 48-years-old male was admitted to Department of Gastroenterology for the investigation of upper abdominal pain. Investigations showed deranged liver biochemistry tests and computed tomography showed widespread ascites and small pleural effusion. Abdominal ultrasonography showed increased size of liver with dilated hepatic veins. The patient was referred to a cardiologist. A transthoracic echocardiogram (TEE) showed normal both ventricular dimensions, dyskinetic motion of intraventricular septum, small pericardial effusion without thickened pericardium. Inferior vena cava (IVC) was dilated with minimal respiratory variation. Because of nonconclusive TTE further diagnostic test including cardiac magnetic resonance imaging (MRI) was recommended. The patient was treated with diuretics and was discharged from hospital after clinical improvement.

After three months he was admitted to Department of cardiology with signs and symptoms of right heart failure. On this admission, TTE showed paradoxical cardiac septal motion ("septal bounce"). Doppler inflow study showed respiratory variations of E-wave in mitral inflow (decreased $>25 \%$ during inspiration) and increased E-wave during inspiration in tricuspid inflow. Pericardium was thickened $(7 \mathrm{~mm})$ now without pericardial effusion. Estimated pulmonary artery pressure was around $40 \mathrm{mmHg}$. The IVC was dilated without respiratory variation. MRI showed intensive T2 signal on pericardium, late gadolinium enhancement: pathologic imbibition in thickened pericardium. Right heart catheterization showed prominent $\mathrm{x}$-descent and y descent, "square root" sign, drop of left ventricular pressure and increased right ventricular pressure during inspiration, equalization of left ventricular end-diastolic pressure and end-diastolic right ventricular pressure $(16 \mathrm{mmHg})$. This finding was consistent with constrictive pericarditis. The patient was referred to a cardiothoracic surgeon and underwent a successful pericardiectomy.

Conclusion: CP should be considered in all patients with unexplained right heart failure. Because diagnosis is sometimes difficult to establish it may be necessary to use multiple diagnostic tools.

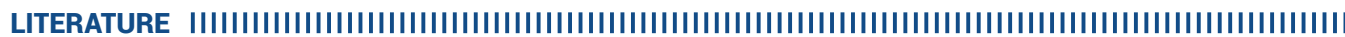

1. Kyriakakis C, Herbst P, Doubell A. Constrictive pericarditis - prevalence, causes and clinical presentation. E-Journal of Cardiology Practice. Vol. 15, № 22 - 08 Nov 2017. Available from: https://www.escardio.org/Journals/E-Journal-of-Cardiology-Practice/Volume-15/Constrictive-pericarditis-prevalence-causes-and-clinical-presentation (February 28, 2019).

2. Lu HT, Ramsamy G, Lee CY, Syed Hamid SRG, Kan FK5, Nordin RB. A Case of Constrictive Pericarditis Associated with Melioidosis in an Immunocompetent Patient Treated by Pericardiectomy. Am J Case Rep. 2018 Mar 19:19:314-319. https://doi.org/10.12659/AJCR.908310 